\title{
Spontaneous spinal epidural hematoma in a patient on oral anticoagulant (Dabigatran)
}

\author{
Mustafa Taskeen ${ }^{1 *}$, Dileep Kadam², Shreyas Wajekar ${ }^{3}$
}

1Junior Resident, ${ }^{2}$ Professor, ${ }^{3}$ Junior Resident, Department of Medicine, Smt Kashibai Navale Medical College and Research Center, Narhe Ambegaon Pune 411041, INDIA.

Email: drmustafataskeen@gmail.com

\section{$\underline{\text { Abstract }}$}

\begin{abstract}
Background: Spontaneous spinal hematoma is a rare condition, which can lead to rapid and irreversible neurological impairment. The incidence in literature is reported to be one per 100,000 population per year and accounts for $0.3-0.9 \%$ of all spinal cord lesions. It can be secondary to an arterio-venous malformation, a cavernoma, a vertebral hemangioma, and frequently associated with provocative factors such as: anticoagulant or anti-aggregating drugs, minor trauma, peridural catheter insertion, severe cough or extreme effort such as delivery, etc. The new generation of nonvitamin $\mathrm{K}$ antagonist oral anticoagulants (NOACs) such as dabigatran, apixaban, and rivaroxaban has more predictable anticoagulant responses and has been shown to be effective in the prevention and treatment of venous thromboembolism. Nontraumatic spinal hematoma as a consequence of anticoagulant treatment is an exceptional complication. A few cases of nontraumatic spinal subdural hematoma related to treatment with NOACs have been reported in the literature, that too with use of rivaroxaban. We report a case of anticoagulant-induced spontaneous spinal hematoma that showed spontaneous rapid resolution of the spontaneous spinal hematoma on conservative management. This case report might help to raise awareness about high index of suspicion in establishing diagnosis \& better idea about the optimal management in anticoagulant-induced spontaneous epidural hematoma of the spine in patient on nonvitamin K antagonist oral anticoagulants (NOACs).
\end{abstract}

Key Word: oral anticoagulant.

\section{*Address for Correspondence:}

Dr Mustafa Taskeen Junior Resident, Department of Medicine, Smt Kashibai Navale Medical College and Research Center, Narhe Ambegaon Pune 411041, INDIA.

Email: drmustafataskeen@gmail.com

Received Date: 22/06/2020 Revised Date: 13/07/2020 Accepted Date: 10/08/2020

DOI: https://doi.org/10.26611/10211534

This work is licensed under a Creative Commons Attribution-NonCommercial 4.0 International License. $(\mathrm{oc})$ BY-NO $^{\mathrm{E}}$

\begin{tabular}{|l|l|}
\hline \multicolumn{2}{|c|}{ Access this article online } \\
\hline Quick Response Code: & Website: \\
\hline & www.medpulse.in \\
\hline
\end{tabular}

\section{INTRODUCTION}

Spontaneous spinal hematoma is a rare condition, which can lead to rapid and irreversible neurological impairment. The incidence in literature is reported to be one per 100,000 population per year and accounts for $0.3-0.9 \%$ of all spinal cord lesions. ${ }^{1,2}$ Spontaneous epidural hematoma of the spine (SEHS) can be secondary to an arterio-venous malformation, a cavernoma, a vertebral hemangioma, and frequently associated with provocative factors such as: anticoagulant or anti-aggregating drugs, minor trauma, peridural catheter insertion, severe cough or extreme effort such as delivery, etc. ${ }^{3}$ The new generation of nonvitamin $\mathrm{K}$ antagonist oral anticoagulants (NOACs) such as dabigatran, apixaban, and rivaroxaban has more predictable anticoagulant responses and has been shown to be effective in the prevention and treatment of venous thromboembolism. Intracranial hemorrhage, posttraumatic spinal hematoma are most severe complications associated with NOACs. ${ }^{4}$ Nontraumatic spinal hematoma as a consequence of anticoagulant treatment is an exceptional complication. A few cases of nontraumatic spinal subdural hematoma related to treatment with NOACs have been reported in the literature, that too with use of rivaroxaban. ${ }^{5,6,7}$ We report a case of anticoagulant-induced SSEH that showed spontaneous rapid resolution of the SSEH on conservative management. This case report 
might help to raise awareness about high index of suspicion in establishing diagnosis and better idea about the optimal management in anticoagulant-induced spontaneous epidural hematoma of the spine in patient on nonvitamin $\mathrm{K}$ antagonist oral anticoagulants (NOACs).

\section{Case Presentation}

A previously healthy, 43 year old male came to SKNMC casualty with complaints of bilateral lower limb weakness since 15 days, difficulty in micturition since 10 days and burning micturition since 10 days. Patient was apparently alright 15 days back when he developed weakness in his bilateral lower limbs, was insidious in onset, gradually progressive, no aggravating or relieving factors were noted. On further enquiry no h/o trauma, fever, abdominal pain, loose stools, vomiting preceding weakness, visual disturbances, slurring of speech , loss of consciousness, headache vomiting, convulsions was noted. The patient also denied any recent history of gingival bleeding, hemoptysis, hematuria, or melena. Patient had history of Right Deep Vein Thrombosis for which he was on anticoagulants (Dabigatran) since last 3 years. No other significant past history. No family history of hypertension, diabetes mellites, tuberculosis, Bronchial Asthma.
Patient had mixed Diet. Patient is a Chronic tobacco chewer, Alcoholic and non-smoker. He recently Complained of urinary retention with abnormal frequency of micturition. Patient had normal bowel habits.

\section{GENERAL EXAMINATION}

During examination patient was concious, oriented to time place and person. Patient was afebrile, with 84 / min radial pulse, regular, equal on both sides, without radiofemoral delay. Patients blood pressure was $124 / 78 \mathrm{~mm} \mathrm{Hg}$ and respiratory rate 16/min. Patient had no pallor, icterus, clubbing, cyanosis ,lymphedenopathy and edema feet. His thyroid, JVP was normal. Other On systemic examination cardiovascular, respiratory and abdominal systems were normal. Cranial nerves examination reveal no abnormality On neurological examination no neurocutaneous markers were noted. No Thickened nerves were noted during examination. Skull, spine were normal. Higher Functions were Normal. Sensory examination revealed decreased sensations to touch temperature and pain between L1 - S1 dermatomal distribution in bilateral lower limbs. No cerebellar signs, signs of meningeal irritation, signs of raised ICT. Motor system examination had normal tone in all 4 limbs .

\section{DEEP TENDON REFLEXES}

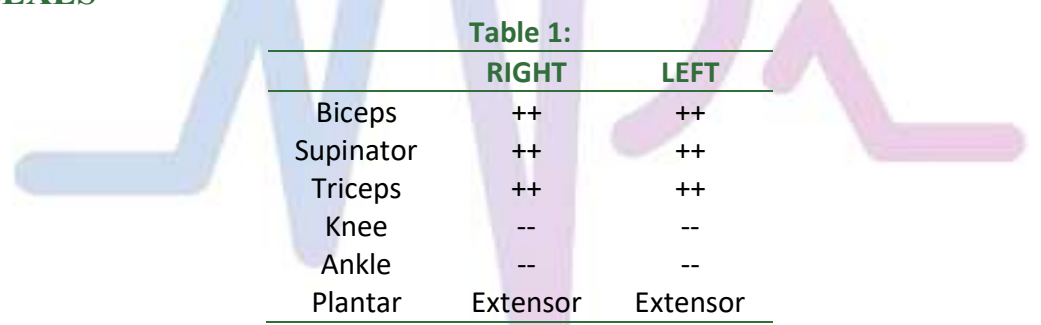

Depending on history and clinical examination compressive myelopathy, transverse myelitis, mononueritis multiplex and multiple sclerosis were kept as differential diagnosis for present case.

\section{DIFFERENTIAL DIAGNOSIS}

\begin{tabular}{|c|c|c|}
\hline DIAGNOSIS & POINTS IN FAVOR & POINTS NOT IN FAVOR \\
\hline Compressive & Acute presentation & No root pain \\
\hline Myelopathy & $\begin{array}{l}\text { Bladder and bowel involvement } \\
\text { Sensory Involvement }\end{array}$ & No Asymmetrical weakness to start with \\
\hline Transverse & Acute presentation & No h/o viral infection \\
\hline Myelitis & $\begin{array}{c}\text { Bladder and bowel involvement } \\
\text { Sensory Involvement }\end{array}$ & $\begin{array}{c}\text { No h/o vasculitis } \\
\text { No h/o pain , tingling sensations }\end{array}$ \\
\hline $\begin{array}{l}\text { Mononueritis } \\
\text { Multiplex }\end{array}$ & $\begin{array}{l}\text { Simultaneous involvement of multiple nerves } \\
\text { can cause paraparesis }\end{array}$ & $\begin{array}{c}\text { No h/o fever } \\
\text { Symmetrical involvement of lower limb } \\
\text { weakness }\end{array}$ \\
\hline Multiple Sclerosis & $\begin{array}{l}\text { Weakness } \\
\text { Bladder bowel dysfunction }\end{array}$ & $\begin{array}{l}\text { No visual /oculomotor abnormalities } \\
\text { No remission exacerbations of neurodeficits }\end{array}$ \\
\hline
\end{tabular}

Routine Investigations were done. Reports are shown in Table 1. Urine analysis had 10-12 Pus cells / hpf and liver function test reports were above normal value. Fundoscopy was normal and no papilledema, no signs of retinopathy on examination. 
Table 3:

\begin{tabular}{ccc}
\hline & INVESTIGATIONS & COMMENTS \\
\hline CBC & Hb 14.2 TLC 7650 Platelets 2.5 L & NORMAL \\
URINE ANALYSIS & Pus cells 10-12 / hpf Epithelial cells occasional Proteins absent Sugar absent & ABNORMAL \\
Sr. Electrolytes & NA+ 137 K+ 3.9 & NORMAL \\
Coagulation studies & PT/ INR, aPTT - normal & NORMAL \\
LFT & Bil T 1.3 Bil Direct 0.4, SGOT 245 SGPT 800 ALT 263 & HIGH \\
RFT & UREA 38 CREATININE 1.1 & NORMAL \\
Blood sugar levels & Fasting Blood sugar : 86 mg $\%$ & NORMAL \\
& Post-prandial Blood sugar :118 mg $\%$ & Negative \\
\hline
\end{tabular}

Further radiological investigations were done. Ultrasound examination was suggestive of "Cholelithiasis with left non obstructing renal calculi with grade 1 fatty liver". On same day venous doppler of bilateral lower limbs was done. Extensive acute thrombosis involving entire extent of right superficial femoral vein, popliteal vein and peroneal veins and left lower limb venous doppler is within normal limits. MRI spine suggestive of hematoma in post epidural space extending from C7 - D7 region with significant compression of spinal cord from D7 - L5 nerve roots.

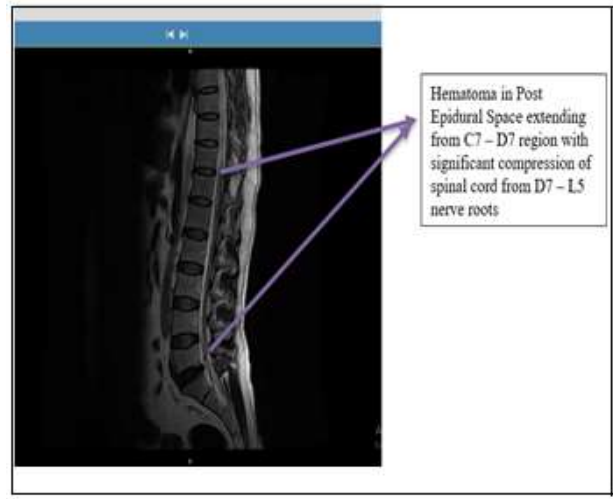

Figure 1

Based on History, general examination and routine investigations, final diagnosis as "right deep vein thrombosis with epidural hematoma with obstructive uropathy" was decided.

- All Hepatotoxic and Nephrotoxic drugs were stopped.

- Patients anticoagulants were withheld.

- Patient was stated with antibiotics to control Urinary tract Infection - Injection Ceftriaxone 2 gm iv bd for 7 days and Tab nitrofurantoin sr 100 $\mathrm{mg}$ twice a day for 7 days was started.

- He was also started with oral steroids $1 \mathrm{mg} / \mathrm{kg}$ per day and later tapered off accordingly. Steroids were started to reduce perilesional edema and inflammation and to minimize compressive symptoms. Inj Methyl prednisolone $1 \mathrm{gm}$ iv once a day for 3 days followed by tab prednisolone 30 $\mathrm{mg}$ once a day for 1 month, followed by tapering dose schedule.

- On day $5^{\text {th }}$ of admission patient had significant improvement in his power of both lower limbs and urinalysis also came negative for pus and
Figure 2

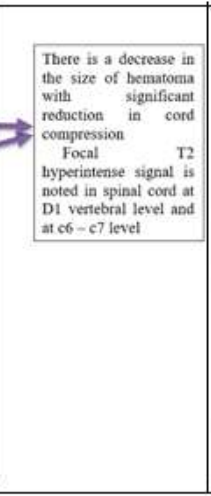

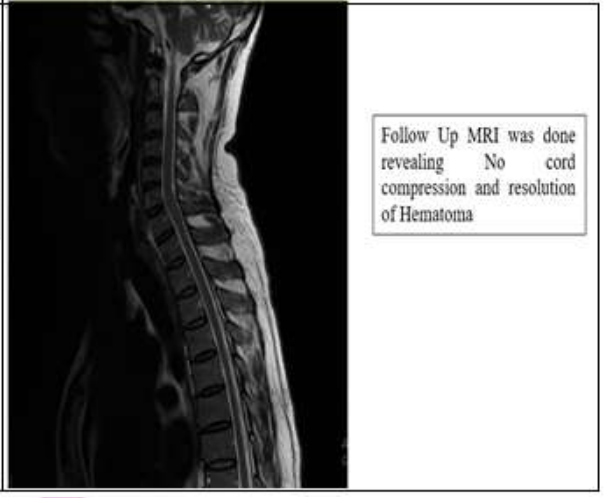

Figure 3 epithelial cells. Patient could void urine without difficulty

\begin{tabular}{ccc} 
Power & Day of admission & After Steroid Supplementation \\
\hline Shoulder & $4 / 5$ & $5 / 5$ \\
Elbow & $4 / 5$ & $5 / 5$ \\
Wrist & $4 / 5$ & $5 / 5$ \\
Hand grip & $4 / 5$ & $5 / 5$ \\
Hip & $3 / 5$ & $5 / 5$ \\
Knee & $3 / 5$ & $5 / 5$ \\
Ankle & $3 / 5$ & $5 / 5$ \\
\hline
\end{tabular}

Patient was discharged on day 7 , with steroid cover and follow up was advised after 1 month. On 19/1/2018.

- After 1 month, repeat MRI DL spine with WSS was done. On MRI study, "There is a decrease in the size of hematoma with significant reduction in cord compression Focal T2 hyperintense signal is noted in spinal cord at D1 vertebral level and at $\mathrm{c} 6$ - c7 level."

Repeat USG abdomen suggestive of renal calculus with no hydronephrosis. Repeat venous doppler of bilateral lower limbs was performed 1 week after discharge suggested of filling defect in the left external iliac and femoral vein with reduction in filling defect 
Follow up on 30/01/2018 -

- Repeat MRI DL spine was done revealed no cord compression and resolution of Hematoma.

- Anticoagulation was started after resolution of hematoma. Tab Dabigatran $75 \mathrm{mg}$ was started once a day for 1 year and was asked to follow up.

\section{DISCUSSION}

Dabigatran etexilate is a novel oral anticoagulant, from the class of univalent direct thrombin inhibitors, initially approved by the Food and Drug Administration in 2010. ${ }^{8}$ Dabigatran is an oral competitive direct inhibitor of both free and clot-bound thrombin with a bioavailability and plasma protein binding of approximately $7 \%$ and $35 \%$, respectively. The drug is primarily $(\geq 80 \%)$ eliminated through the kidney in an unchanged form and has a terminal elimination half-life of 12 to 17 hours after multiple doses in healthy patients. ${ }^{9}$ The PT and the INR lack any reliable correlation to dabigatran plasma levels and should not be used for the monitoring of dabigatran. ${ }^{10}$ True clinical risks and complications of dabigatran anticoagulation therapy are still being elucidated. ${ }^{11}$ Epidural or spinal hematomas may occur in patients treated with PRADAXA (oral dabigatran) who are receiving neuraxial anesthesia or undergoing spinal puncture. These hematomas may result in long-term or permanent paralysis. $^{12}$ The most important factor identified as contributing to spontaneous epidural hematoma of the spine (SEHS) are a hemorrhagic diathesis from either medications or various disease states. Various medications such as antiplatelet, anticoagulant, or thrombolytic medications, such as aspirin, warfarin, heparin, tissue plasminogen activator, and streptokinase have been reported to be associated with SEHS. ${ }^{13}$ Spontaneous epidural hematoma of the spine (SEHS) occurs most commonly in the dorsal or the cervico-dorsal spine. ${ }^{14}$ Nontraumatic spontaneous spinal subdural hematoma should be distinguished from spinal subarachnoid hemorrhage, spinal epidural hemorrhage, or intraspinal hemorrhage. ${ }^{15}$ Multiplanar spinal MRI is very useful for the initial diagnosis and assessment of the extent of the lesion and degree of spinal cord compression. CT of the spinal cord is also an option if MRI is not possible. Congress of Neurological Surgeons and the American Association of Neurological Surgeons issued updated guidelines in 2013, they recommend against the use of steroids early after an acute spinal cord injury. ${ }^{16}$ But there ars no randomized trials done based on the use of steroid in SEHS. In some of the studies, a low dose of steroid was used in SEHS. ${ }^{1}$ In present case, we had good results with steroids. Idarucizumab is a reversal agent for dabigatran which is recently approved by FDA but limited availability and experience with these agents are major factor less use. ${ }^{17}$ Nontraumatic spontaneous spinal subdural hematoma is a neurological complication of the use of dabigatran. Physicians should be aware of the increasing incidence of severe bleeding complications associated with the increasing use of NOACs. Recovery of the neurological deficit depends on prompt diagnosis with MRI scans, area of hematoma and early management as conservative treatment or surgical evacuation of the hematoma. The primary treatment modality in SSEH is decompressive surgery, as a delay in intervention may result in a poor clinical outcome. Although the number of reports in the literature is increasing regarding spontaneous resolution of the SSEH, no evidence based guideline is available on the optimal treatment of the SSEH. ${ }^{1}$ In present case, we successfully managed patient with conservative management.

\section{REFERENCES}

1. Kim KT, Cho DC, Ahn SW, Kang SH. Epidural hematoma related with low-dose aspirin: complete recovery without surgical treatment. J Korean Neurosurg Soc 2012;51:308311.

2. Yang SM, Kang SH, Kim KT, Park SW, Lee WS. Spontaneous spinal epidural hematomas associated with acute myocardial infarction treatment. Korean Circ J 2011;41:759-762

3. Shin JJ, Kuh SU, Cho YE. Surgical management of spontaneous spinal epidural hematoma. Eur Spine J. 2006;15:998e1004.

4. Y. M. Mekaj, A. Y. Mekaj, S. B. Duci, and E. I. Miftari, "New oral anticoagulants: their advantages and disadvantages compared with vitamin $\mathrm{K}$ antagonists in the prevention and treatment of patients with thromboembolic events," Therapeutics and Clinical Risk Management, vol. 11, pp. 967-977, 2015.

5. J. M. Castillo, H. F. Afanador, E. Manjarrez, and X. A. Morales, "Non-traumatic spontaneous spinal subdural hematoma in a patient with non-valvular atrial fibrillation during treatment with rivaroxaban," American Journal of Case Reports, vol. 16, pp. 377-381, 2015.

6. C. Dargazanli, N. Lonjon, and G. Gras-Combe, "Nontraumatic spinal subdural hematoma complicating direct factor $\mathrm{Xa}$ inhibitor treatment (rivaroxaban): a challenging management," European Spine Journal, vol. 25, no. 1, pp. 1-4, 2016.

7. M. Zaarour, S. Hassan, N. Thumallapally, and Q. Dai, "Rivaroxaban-induced nontraumatic spinal subdural hematoma: an uncommon yet life-threatening complication," Case Reports in Hematology, vol. 2015, Article ID 275380, 5 pages, 2015.

8. Pradaxa US Prescribing Information. Ridgefield: Boehringer Ingelheim Pharmaceuticals, Inc; 2015. Available at: http://docs.boehringeringelheim.com/Prescribing Information/PIs/Pradaxa/Pradaxa.pdf.

9. Stangier J. Clinical pharmacokinetics and pharmacodynamics of the oral direct thrombin inhibitor dabigatran etexilate. Clin Pharmacokinet. 2008; 47:285295. 
10. Douxfils J, Mullier F, Robert S, Chatelain C, Chatelain B, Dogne JM. Impact of dabigatran on a large panel of routine or specific coagulation assays. Laboratory recommendations for monitoring of dabigatran etexilate. Thromb Haemost. 2012;107:985-997.

11. Connolly SJ, Ezekowitz MD, Yusuf S, Eikelboom J, Oldgren J, Parekh A, et al... Dabigatran versus warfarin in patients with atrial fibrillation. $N$ Engl $\mathrm{J}$ Med 2009;361:1139e51.

12. PRADAXA $®$ (dabigatran etexilate mesylate) capsules, for oral use Initial U.S. Approval: 2010 accessed from www.fda.gov/medwatch.

13. Binder KD, D Sonne C, Lawton TM. Spinal epidural hematoma. Neurosurg Q. 2004;14:51e59.
14. V.B. Moises Heleno, B. Raphael, Conservative treatment of large spontaneous spinal extradural hematoma, Arq. Neuropsiquiatr. 68 (2010) 130-131.

15. J. G. Heckmann, "Spinal subarachnoid haemorrhage in cortical superficial siderosis after apixaban and clopidogrel therapy," Journal of Thrombosis and Thrombolysis, vol. 41, no. 4, pp. 654-655, 2016.

16. Hadley MN, Walters BC. Guidelines for the management of acute cervical spine and spinal cord injuries. Neurosurgery. 2013;72:1e259.

17. P. Gelosa, L. Castiglioni, M. Tenconi et al..., "Pharmacokinetic drug interactions of the non-vitamin $\mathrm{K}$ antagonist oral anticoagulants (NOACs)," Pharmacological Research, vol. 135, pp. 60-79, 2018.

\section{Source of Support: None Declared Conflict of Interest: None Declared}

\section{Policy for Articles with Open Access:}

Authors who publish with MedPulse International Journal of Medicine, Print ISSN: 2550-7583, Online ISSN: 2636-4751 agree to the following terms: Authors retain copyright and grant the journal right of first publication with the work simultaneously licensed under a Creative Commons Attribution License that allows others to share the work with an acknowledgement of the work's authorship and initial publication in this journal. Authors are permitted and encouraged to post links to their work online (e.g., in institutional repositories or on their website) prior to and during the submission process, as it can lead to productive exchanges, as well as earlier and greater citation of published work. 